Original Research Paper

\title{
Future Water Budgets and Water Supply Stress under Climate Change and Urbanization in the Upper Neuse River Basin, North Carolina, USA
}

\author{
${ }^{1}$ Michelle Tong Sun, ${ }^{2}$ Ge Sun, ${ }^{3}$ Chong Liu, ${ }^{2}$ Jennifer Anne Moore Myers and ${ }^{2}$ Steven George McNulty \\ ${ }^{I}$ North Carolina School of Science and Mathematics, Durham, NC, USA \\ ${ }^{2}$ United States Department of Agriculture Forest Service, \\ Eastern Forest Environmental Threat Assessment Center, Southern Research Station, Raleigh, NC, USA \\ ${ }^{3}$ Sate Key Laboratory for Information Engineering in Surveying, \\ Mapping and Remote Sensing, Wuhan University, Wuhan, China
}

Article history

Received: 02-03-2015

Revised: $15-04-2015$

Accepted: 08-05-2015

Corresponding Author:

Ge Sun

United States Department of

Agriculture Forest Service,

Eastern Forest Environmental

Threat Assessment Center,

Southern Research Station,

Raleigh, NC, USA

Email: gesun@fs.fed.us

\begin{abstract}
Urbanization and climate change are the two major threats to watersheds and the environment in the United States. It is imperative to understand the sensitivity of hydrologic responses to climate and urbanization across different physiographic regions in order to formulate sound watershed management strategies and policies. This study evaluated a watershed water balance model, Water Supply Stress Index (WaSSI), with measured historic streamflow data for the Upper Neuse River basin in central North Carolina. A user-friendly web version of the WaSSI model was applied to examine how climate change and potential urbanization over the next 50 years may affect streamflow (or water yield) of this river basin and water supply stress (water demand/water supply). Our simulation study suggested that urbanization could increase water yield $(8 \%)$, while climate change could reduce $(30 \%)$ water yield depending on future changes in precipitation and warming potential in the study basin. Climate change is likely to overwhelm the basin-wide impacts of urbanization in terms of its influences on water supply stress, but urbanization may aggravate the environmental problems by increasing stormflow and water quality degradation under a changing climate. Future climatic change models should reduce the uncertainty of climate projection in precipitation, a major control on watershed hydrology.
\end{abstract}

Keywords: Climate Change, Hydrologic Modeling, Urbanization, Water Yield, Water Supply

\section{Introduction}

Water is essential to life (McDonald et al., 2011). Water has been regarded as one of the most important natural resources, even more precious than oil in the future. Water sustains many economic activities including agriculture, transportation, manufacturing, recreation and tourism (Sun et al., 2008; 2013). In turn, humans have altered the water resource distribution, quality and availability directly through water use or indirectly through change in land use patterns, urbanization and local and global climate (Sun and Lockaby, 2012).

Climate change is the long-term change in weather patterns, including precipitation and temperature. It is caused by an increase in greenhouse gasses in the atmosphere (IPCC, 2014) and it is well known that climate change has profound impacts on stream hydrology, water quantity, water quality and water supply to ecosystems and humans (McDonald et al., 2011; NCA, 2014). Warmer temperatures caused by excess greenhouse gas emissions have been linked to acceleration of hydrologic cycles by increasing the rate of evapotranspiration. The results may leave some areas in drought and others with excess precipitation. Heavy downpours increase surface runoff which can wash pollutants and trash into water supply and recreational areas (Kundzewicz et al., 2007; CCSP, 2014). This could seriously impact water quality by causing problems for water infrastructure. In some areas of the country the effects of climate change can cause a shift in the 
balance of water supply and demand (Sun et al., 2008; Caldwell et al., 2011; 2012). This shift will pressure managers to meet the changing needs of communities. We need to better understand and predict future climate change impacts on water resources.

The piedmont region, which contains the Research Triangle Park (RTP) area, in North Carolina is known for its vigorous economy accompanied by rapid population growth and land use change in the past two decades. For example, the Upper Neuse River Basin (UNRB) (in eastern North Carolina (Fig. 1) has a population of 190,000 people and it is projected that over the next 25 years, population will grow by $53 \%$ to 280,000 (http://unrba.org). Under uncontrolled growth, the watershed will see dramatic loss of forest land to urbanization. It was projected that urban and suburban areas could change from the current 18 to $60 \%$ in 25 years. The City of Durham, a major city within UNRB, has experienced a $40 \%$ population growth from the 1990 to 2010 s. Growth can lead to increased water pollution from storm runoff and non-point source pollution (O’Driscoll et al., 2010) and is a major environmental concern in city planning in the southeastern US.

During the past decade, the waters of the UNRB have degraded and have been challenged to meet the demands of society and the environmental standards. Falls Lake is the primary source of drinking water for the City of Raleigh (Fig. 1). Concerns over water pollution and drinking supply for Raleigh have arisen amid the rapid population growth, urban sprawl and dynamic climate in the basin. The Falls Lake reservoir, constructed between 1978 and 1981, has emerging water quality and quantity issues. It has a surface area of around 12,500 acres and is the primary source of drinking water for Raleigh. The Falls Lake is a shallow Piedmont lake and thus it is difficult to maintain its water quality for chlorophyll- $a$ because of its geology and topographic location downstream of urban areas. Now the water in Falls Lake is considered 'impaired,' meaning the water quality does not meet North Carolina standards.

Therefore, better understanding of the water budgets and water supply stress of the UNRB at present and in the future will allow policy makers to make informed management decisions. Decisions made on sound hydrological science will benefit local citizens and sustain the region's environmental resources.

The objectives for this study were to: (1) construct a water budget for the UNRB using the WaSSI hydrological model; (2) verify model performance with measured streamflow and ET data; and (3) assess the individual and combined potential impacts of future climate change and urbanization on the streamflow and water supply stress for the UNRB.

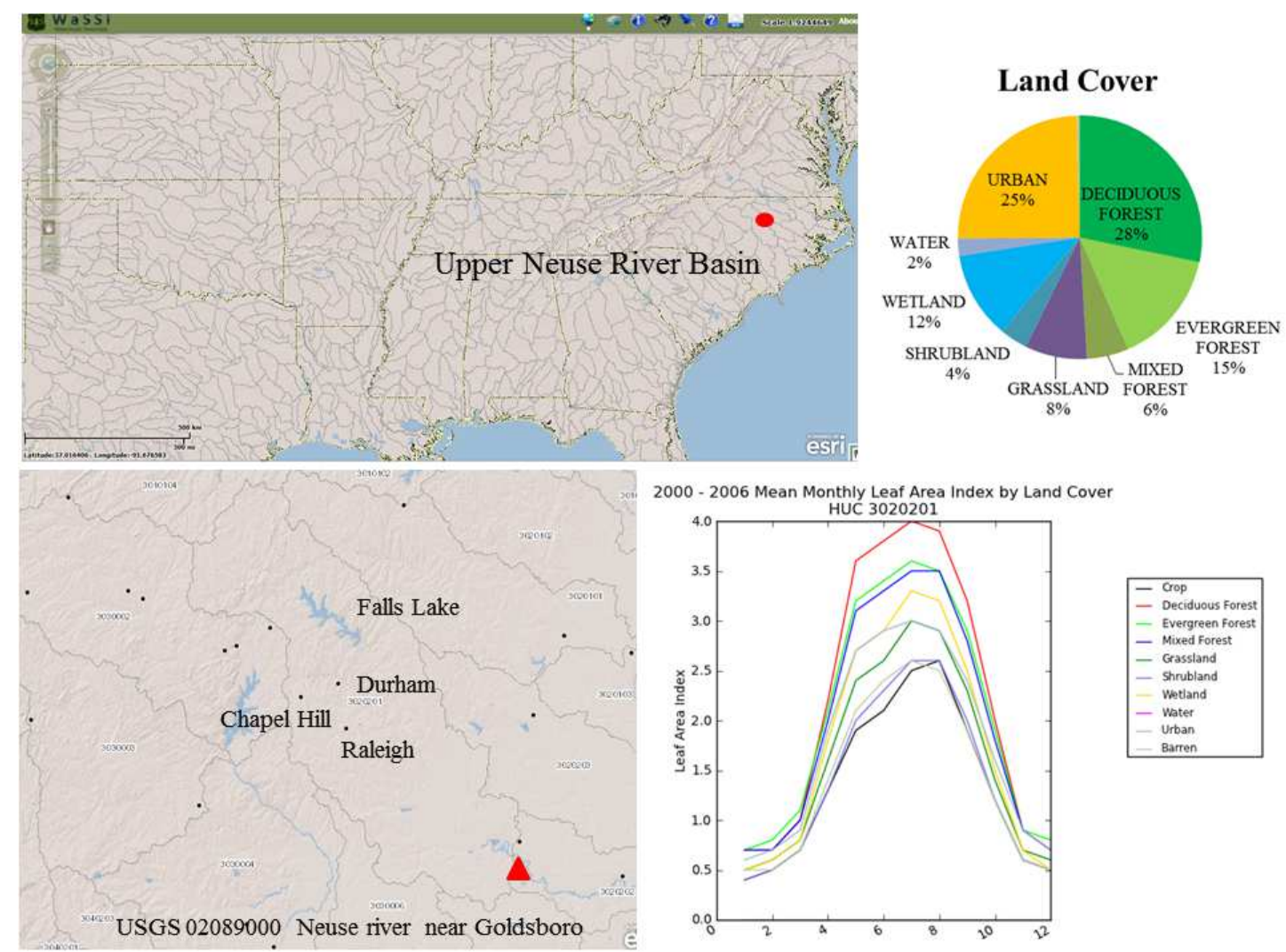

Fig. 1. Location, land use composition and leaf area index of the Upper Neuse River Basin (HUC 03020201) in North Carolina 


\section{Research Methods}

\section{The Upper Neuse River Basin (UNRB)}

This study focuses on the Upper Neuse River Basin (UNRB) in North Carolina (Fig. 1). The UNRB intersects several counties from the headwaters (Person Orange), the middle reach (Durham, Granville), to the lower reach (Wake, Johnson, Wayne). The basin is identified with an 8-digit Hydrologic Unit Code (HUC) number of 03020201. The UNRB, located in the piedmont physiographic region, has a total catchment area of 6,232 $\mathrm{km}^{2}$ and is comprised of several important tributaries such as the Flat, Eno and Little Rivers. The basin contains nine public drinking water supply reservoirs that serve about 500,000 people including Falls Lake Reservoir, Raleigh's major water source. The basin also contains many parks, such as the Eno River State Park, an important recreational area for North Carolina residents.

\section{Watershed Land Cover Characteristics}

The watershed is dominated by forest $(56 \%)$, cropland $(26 \%)$ and urban land (18\%) use. The land cover data for this study were aggregated from the 2006 National Land Cover Dataset $(30 \times 30 \mathrm{~m}$ resolution based on Lands at imagery and classified into $17 \quad$ cover types (http://www.mrlc.gov/nlcd06_data.php).

\section{Climate Data for Model Validation and Predictions}

The historic climate dataset $(4 \times 4 \mathrm{~km}$ resolution) for the 1961-2010 time period was derived from the Precipitation Elevation Regression on Independent Slopes Model (PRISM) database (Daly et al., 2008). These data were used to validate the WaSSI model by comparing simulated streamflow with measured at one hydrologic gauging station maintained by the US Geological Survey (USGS).

Future climate data were acquired from downscaled by General Circulation Model (GCM) projections (Coulson et al., 2010). Two climate change scenarios under greenhouse gas emission storyline SRES A1B were used to examine how future climate change may affect water resources in the UNRB. The two GCMs are CGCM3, developed by the Canadian Centre for Climate Modeling and Analysis and MIROC3.2, developed by the Center for Climate System Research, National Institute for Environmental Studies and Frontier Research Center for Global Change in Japan. These two GCMs represent two very different future climate conditions, warm (CGCM3) and drier and hot (MIROC3.2), in comparison to historic climate.

\section{The WaSSI Model}

This study used the USDA Forest Service Water Supply Stress Index (WaSSI) model (Fig. 2). WaSSI was designed and applied to the southeastern US at the 8-digit
HUC watershed scale to estimate watershed water balances, carbon balances and water supply and demand on a monthly time step (Sun et al., 2011a; Caldwell et al., 2012; Sun et al., 2015). A user friendly version of model is available online athttp://www.forestthreats.org/research/tools/WaSSI.Users have the option to run multiple future scenarios to represent land use change (e.g., reforestation, urbanization) under historic climate (1961-2010) or 13 historic and future climate scenarios (1961-2099). Both model inputs and outputs can be viewed online and can be downloaded as charts, maps, or text files for additional analysis (Fig. 3).

The WaSSI model is an integrated, process-based simulator that describes key ecohydrological processes at a broad scale (Sun et al., 2011b; Caldwell et al., 2012; Sun et al., 2015). It simulates water and carbon balances, including Evapotranspiraton (ET), soil water storage, runoff or water yield (Q) and ecosystem productivity (GPP) for each of eight land cover types within a given watershed and then aggregates these fluxes to the basin scale. Three sub-models are integrated within the WaSSI model framework. The water balance sub-model computes ecosystem water use (i.e., ET) and Q generated from each watershed. The carbon balance sub-model simulates monthly carbon gains (GPP) and losses (i.e., ecosystem respiration) in each watershed as functions of ET and GPP, respectively (Sun et al., 2011a). The water supply and demand sub-model routes and accumulates Q through the river network according to topological relationships between adjacent watersheds, subtracts consumptive water use by humans from river flows and compares water supply to water demand to compute the water supply stress index. In this study, we focused on monthly and annual water yield (Q) and annual Water Supply Stress Index (WaSSI). By definition, water yield is the total flow generated from each basin as a function of monthly precipitation, ET and change in soil water storage. WaSSI is defined as the ratio of water demand over water supply. Water demand data were provided by periodic USGS water use surveys. The water use data for year 2005 was used in this study (Kenny et al., 2009). Water supply refers to the sum of streamflow from the adjacent watersheds upstream, water yield generated from the current watershed and groundwater withdrawals in each month. For a complete description of the WaSSI model algorithms, readers are referred to the WaSSI User's Guide (http://www.forestthreats.org/research/tools/WaSSI/WaS SIUserGuide_english_v1.1.pdf).

The WaSSI model $\overline{\text { has }}$ been used to assess the combined or separate effects of climate change, land cover change and anthropogenic water use on historic and future water supply stress and ecosystem productivity over the US, Mexico, China and several African countries (Lockaby et al., 2011; Averyt et al., 2013; Tavernia et al., 2013; Liu et al., 2013; McNulty et al., 2015). For this study, the focus is on the combined impacts of urbanization and climate change on annual and long term water yield. 


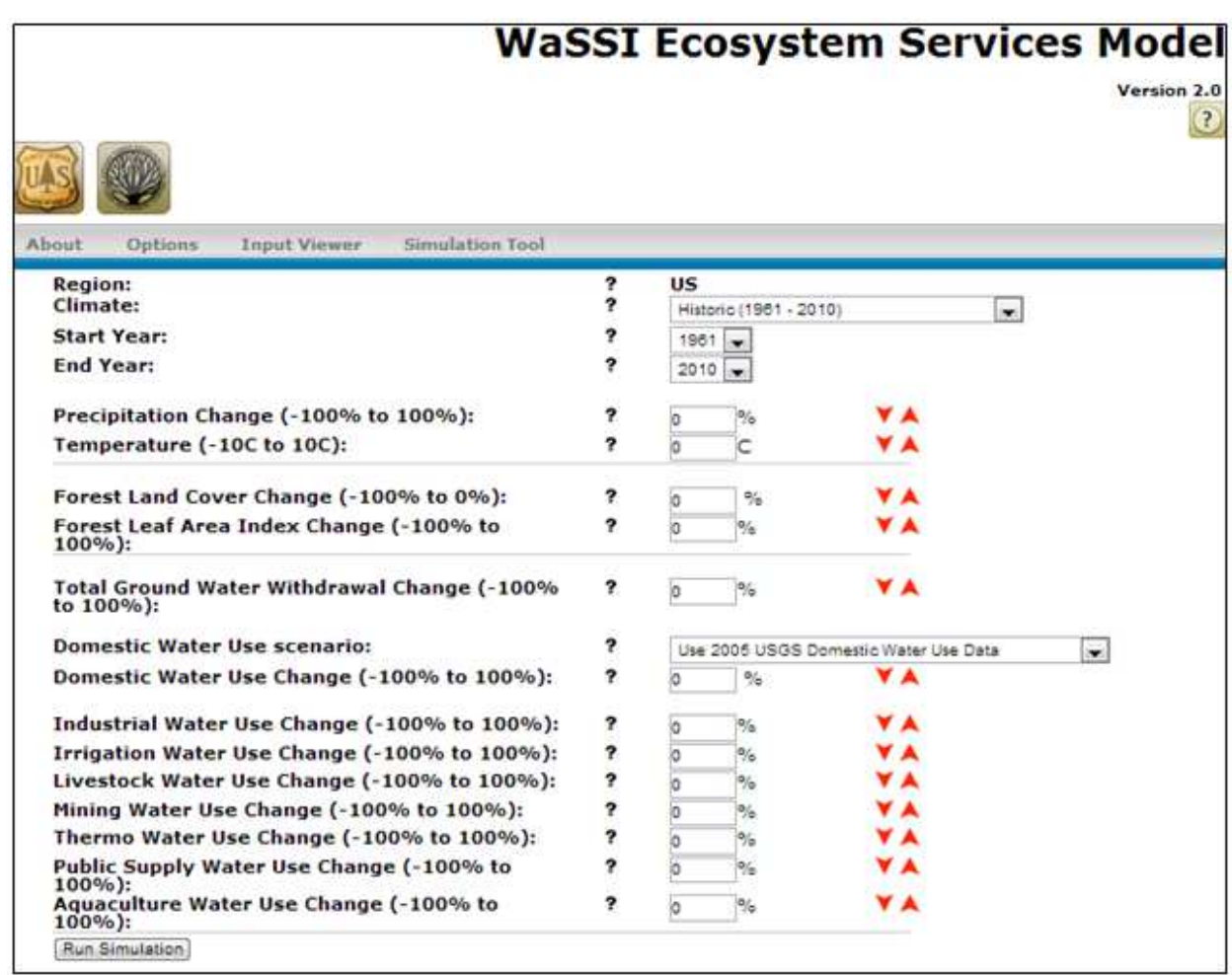

Fig. 2. A screenshot of the WaSSI online model user interface that allows the users to run the model online using different combinations of land covers and GCMs climate change scenarios or designed by the user

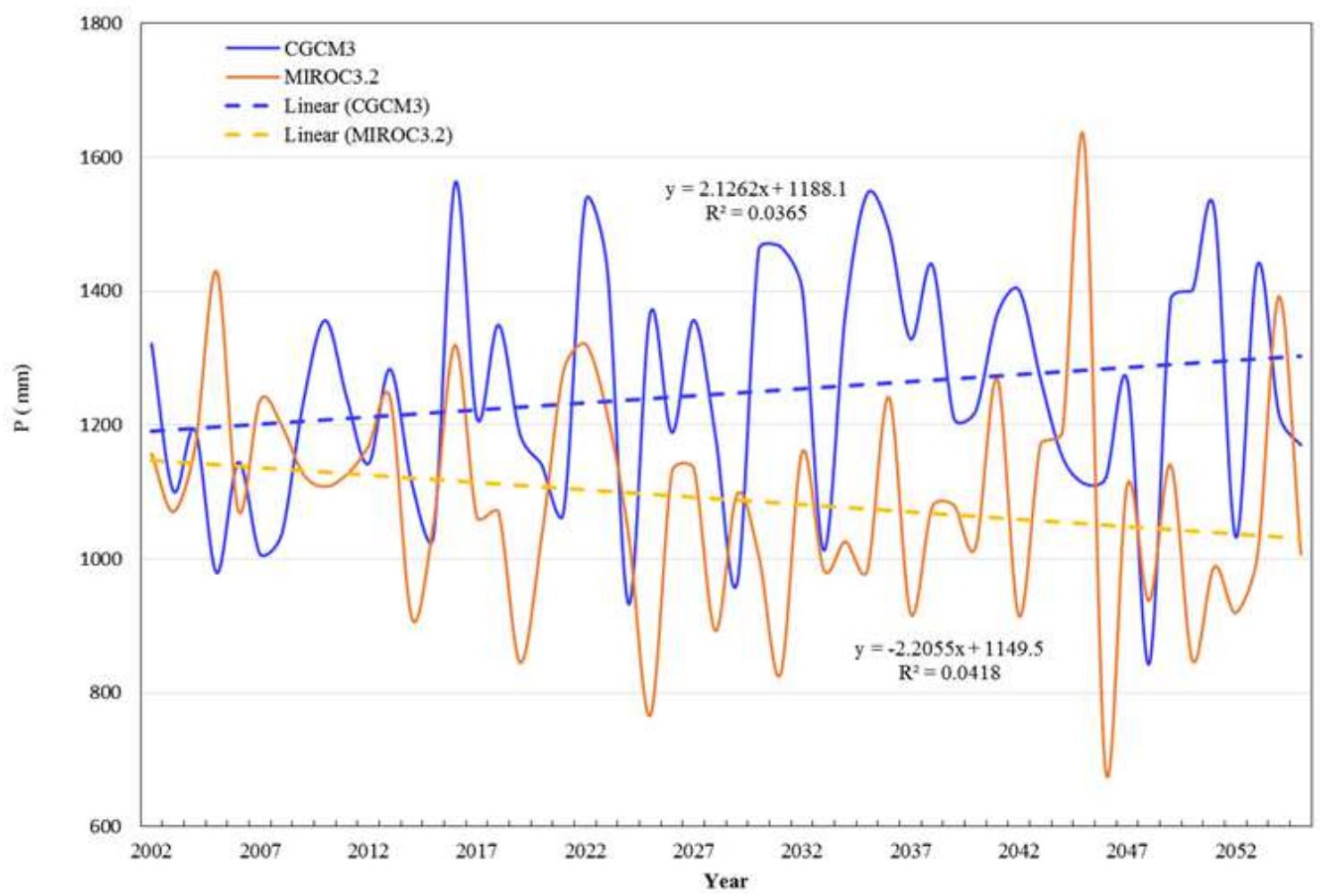

Fig. 3.Projected trend of annual precipitation for the Upper Neuse River Basin in North Carolina by two General Circulation Models (2002-2055) 


\section{Model Validation}

The WaSSI model was designed for modeling watershed functions at the regional or continental levels. It is essential to evaluate the model's capability to simulate water balances locally and model uncertainty can be identified and quantified. Therefore, we first evaluated model performance using measured monthly streamflow data. However, the USGS Neuse River near Goldsboro (Station number: 02089000, Latitude $35^{\circ} 20^{\prime} 15^{\prime}$, Longitude $\left.77^{\circ} 59^{\prime} 51^{\prime \prime}\right)$ started to operate only in 2007. Therefore we used reanalyzed monthly streamflow data by the USGS to represent flow measurements for the study basin (http://waterwatch.usgs.gov/index.php?id=romap3\&sid= $\mathrm{w}$ _ download). We evaluated the model performance in simulating monthly streamflow using Coefficient of Determination $\left(\mathrm{R}^{2}\right)$ and the slope of the linear regression model (simulated vs measured streamflow) and the Nash-Sutcliffe Efficiency (Nash and Sutcliffe, 1970).

Evapotranspiration (ET) is a major component of the watershed water balances and modeling errors of streamflow are often caused by model inadequacy in ET models (Sun et al., 2011b). Therefore, the model's performance was also evaluated with published global MODIS ET by Mu et al. (2011) and modeled ET by from EC-MOD by Xiao et al. (2014). Both datasets have a $1 \times 1 \mathrm{~km}$ grid resolution and were scaled to the HUC- 8 watershed for model comparison purposes. The
MODIS ET data were developed using reanalysis of surface meteorological data with MODIS land cover, albedo, LAI and the Fraction of Absorbed Photo synthetically Active Radiation (FPAR). The ECOMOD data represent 'scaled up' ET data of eddy covariance measurements with machine learning technique (Xiao et al., 2014). The algorithms for regional and global ET mapping and monitoring have been evaluated with AmeriFlux flux datasets.

\section{Model Applications}

WaSSI was applied to six simulation scenarios derived from combinations of climate and urbanization projections that may represent future climate and land use conditions for the UNRB in 2050 (Table 1). The first scenario (S0) is the baseline, while $\mathrm{S} 1$ represents converting $50 \%$ forest land to urban and population from 1.2 million in 2010 to 1.9 million in 2050, a $62 \%$ increase (Zarnoch et al., 2010). The percentage of forest land area was reduced from 56 to $28 \%$ and urban land area was increased from the current 18 to $48 \%$ in 2050 .

The S2-S5 scenarios represent future climate combined with increased population and with or without land use change. The CGCM3 GCM predicted a slight increase in precipitation (2 mm per year) (Fig. 3) and in PET (1.7 mm per year) (Fig. 4), while the MICRO3.2 GCM predicted a decrease in $\mathrm{P}$ ( $2 \mathrm{~mm}$ per year) and a large increase in PET (2.6 mm per year).

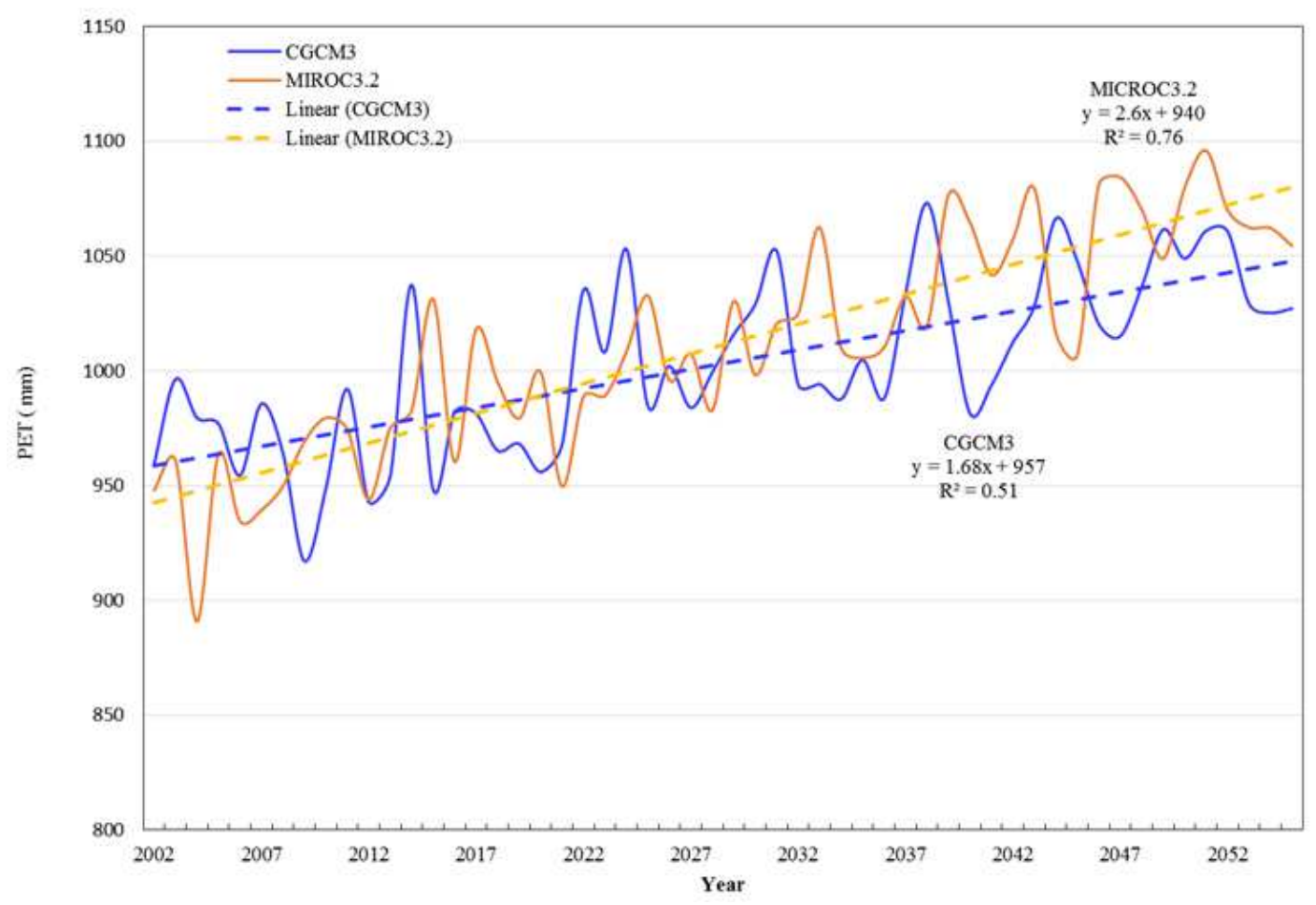

Fig. 4. Projected trend of annual potential evapotranspiration (PET) for the Upper Neuse River Basin in North Carolina by two General Circulation Models under the A1B emission storyline (2002-2055) 
Table 1. Simulation scenarios by the WaSSI model to examine the combined hydrologic effects of climate change and urbanization

\begin{tabular}{llll}
\hline Scenarios & Climate & Land use & Population \\
\hline S0 & Historic (1961-2010) & Baseline (2006) & 2005 \\
S1 & Historic (1961-2010) & $50 \%$ Forest converted to urban & 2050 IPCC SRES A1B scenario \\
S2 & CGCM3 & Baseline (2006) & 2050 \\
S3 & MIROC3.2 & Baseline (2006) & 2050 \\
S4 & CGCM3 & $50 \%$ Forest converted to urban & 2050 \\
S5 & MIROC3.2 & $50 \%$ Forest converted to urban & 2050 \\
\hline
\end{tabular}

\section{Evaluation of Hydrologic Variables}

In this study, we focused on two hydrologic variables, annual water yield ( $Q$ in $\mathrm{mm} /$ year) at the outlet of UNRB and water supply stress (WaSSI) under the six scenarios. $Q$ indicates the water production capability of the watershed that is affected only by climate and land cover types while WaSSI reflects the influences of both nature (i.e., climate change and variability) and humans (i.e., urbanization and increased domestic water use accompanying population growth).

\section{Results}

\section{Modeled Validation and Water Budgets}

WaSSI captured monthly streamflow dynamics (Fig. 5) but overestimated the flow in September of 1999 when Hurricane Floyd hit North Carolina, resulting in widespread flooding in the UNRB. Similarly, the ET patterns modeled by WaSSI matched well with other ET estimates based on remote sensing techniques (Mu et al., 2011) and ET data by Xiao et al. (2014). However, compared to MODIS-ET, WaSSI modeled ET rates were much lower during the growing season from April to September but much higher during the dormant season (Fig. 6).

At the annual time step, WaSSI modeled ET was lower than the MODIS-ET and the 'measured ET values'-the differences between measured $\mathrm{P}$ and $\mathrm{Q}$, but higher than the estimated annual ET by Xiao et al. (2014) EC-MOD ET method (Fig. 7).

The measured mean annual precipitation $(\mathrm{P})$ and streamflow (Q) for the 2001-2010 period was 1121 $\mathrm{mm}$ and $259 \mathrm{~mm}$, respectively (Fig. 8). Modeled ET and water yield was 728 and $324 \mathrm{~mm}$, or 65 and $35 \%$ of $\mathrm{P}$, respectively. The WaSSI model overestimated Q by $91 \mathrm{~mm}$ per year or $27 \%$ on average when compared to measured Q. The overestimations were mainly found in wet years (2003, 2006) (Fig. 8). The simulated monthly Q was highly correlated with measured $\mathrm{Q}$ with a $\mathrm{R}^{2}$ of 0.81 and Nash-Sutcliffe Efficiency of 0.71 .

\section{Impacts of Urbanization on Water Yield}

The long-term baseline (S0, 1961-2010) mean annual streamflow was estimated as $437 \mathrm{~mm}$ (Fig. 8). As expected, converting $50 \%$ of forests to urban (S1) would increase Q by $34 \mathrm{~mm}$ per year or $8 \%$ due to the reduction in ET (Fig. 8). Urban land covers had lower Leaf Area Index (LAI) thus lower ET than forests (Sun et al., 2011b; Sun and Lockaby, 2012).

\section{Impacts of Urbanization + Climate Change on Water Yield}

The mean annual water yield did not change much during 2002-2055 under the CGCM3 scenarios (S2, S4) (Fig. 10) although P increased by $2 \mathrm{~mm}$ per year (Fig. 3). This was because PET increased significantly at $1.7 \mathrm{~mm}$ per year (Fig. 4). In contrast, Q declined significantly under the MIROC3.2 climate scenarios (S3, S5) by 2.6 $\mathrm{mm} /$ year) (Fig. 10) as a result of decreases in $\mathrm{P}$ and increases in PET. Under the CGCM3 climate change scenario (S2), the mean water yield in 2050 (2045-2055) was almost identical $(437 \mathrm{~mm})$ to the baseline in 2005 , although $\mathrm{P}$ increased $64 \mathrm{~mm}$ or $6 \%$. This was due to the rise in air temperature and PET of $129 \mathrm{~mm}$ or $14 \%$, resulting in a decrease in actual ET. However, water yield decreased greatly by $132 \mathrm{~mm}$, or $25 \%$, under the MIROC3.2 climate change scenario (S3). The change in water yield was a result of the combination of the $104 \mathrm{~mm}$ or $9 \%$ decrease in $\mathrm{P}$ and an increase in air temperature that resulted in an increase in PET of $154 \mathrm{~mm}$ or $17 \%$. Because urbanization increased $\mathrm{Q}$, the combination of urbanization and climate (S4, S5) resulted in a moderate increase in Q compared to S2 and S3. However, the urbanization effect could not compensate the large decline in Q for MIROC3.2 climate scenario (S3, S5).

\section{Impacts of Urbanization and Climate Change on Water Supply Stress (WaSSI)}

The baseline annual water stress index (WaSSI) was about 0.287 , meaning $28.7 \%$ of the water supply was subject to water withdrawal from the basin (Fig. 9). This index was lower under the urbanization scenario (S1) as a result of increased Q and thus total water supply. Under S2, WaSSI increased slightly (from 0.287 to 0.3 ) as a result of population growth that required more water for domestic use. Due to the large decrease in $\mathrm{Q}$, thus a decrease in water supply for the S3, WaSSI increased greatly to 0.458 . Urbanization alleviated some of the water supply stress caused by MIROC3.2 to 0.40 (S5). 


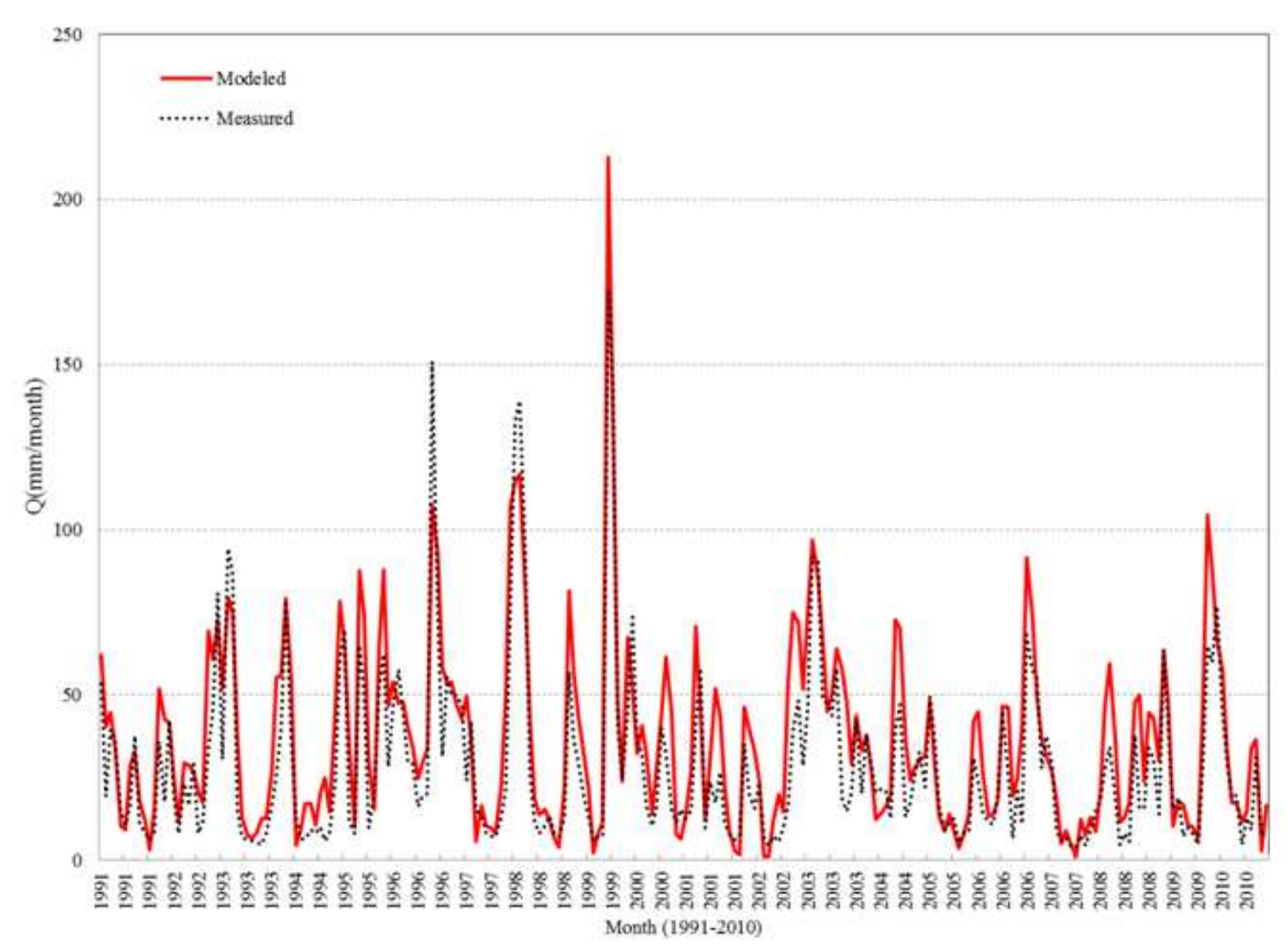

Fig. 5. Modeled and measured monthly streamflow for the Upper Neuse River Basin in North Carolina (1991-2010)

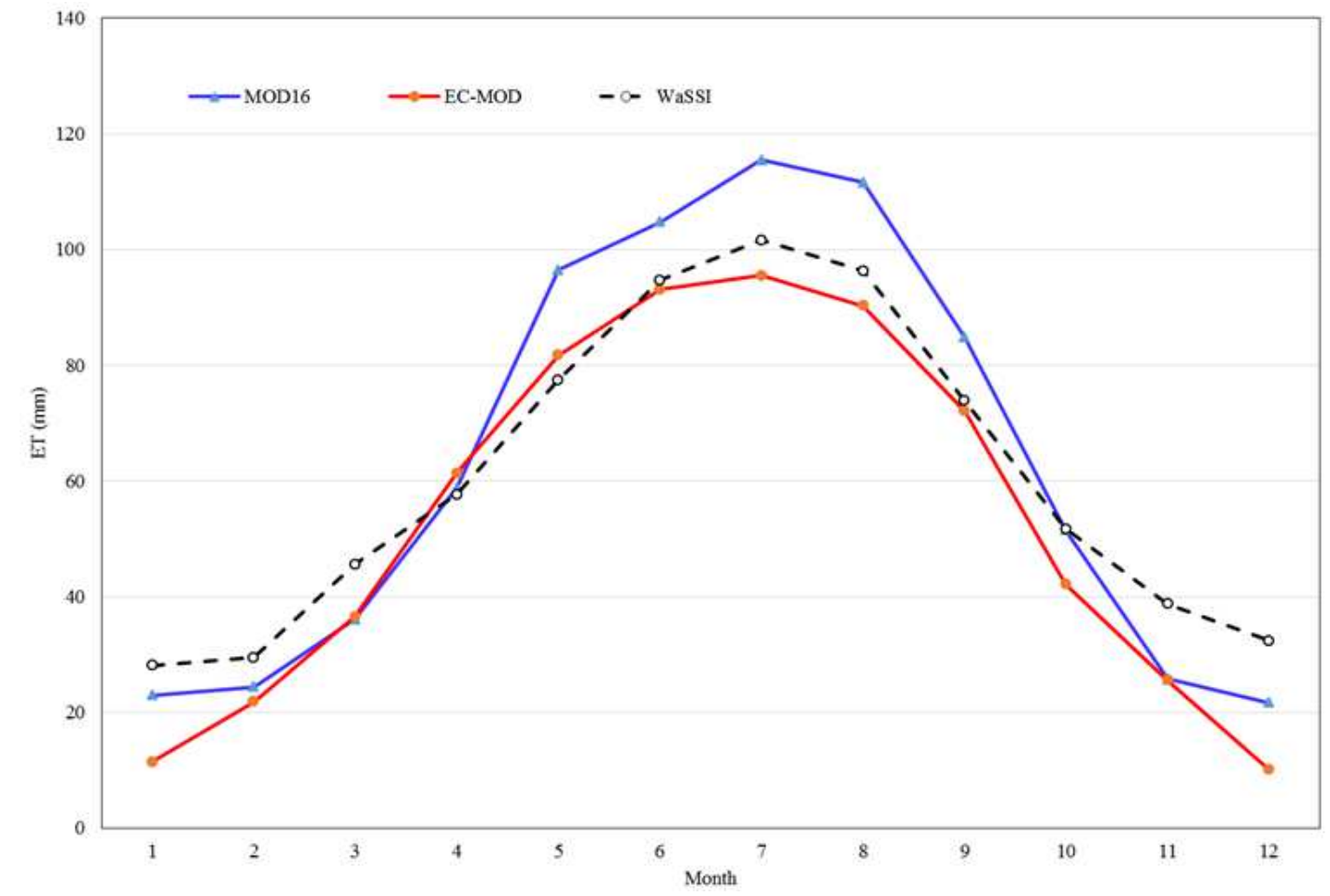

Fig. 6. A comparison of monthly modeled ET and estimated ET by the MODIS-ET (Mu et al., 2011) and EC-MOD by Xiao et al. (2014) for the Upper Neuse River Basin in North Carolina (2001-2010) 


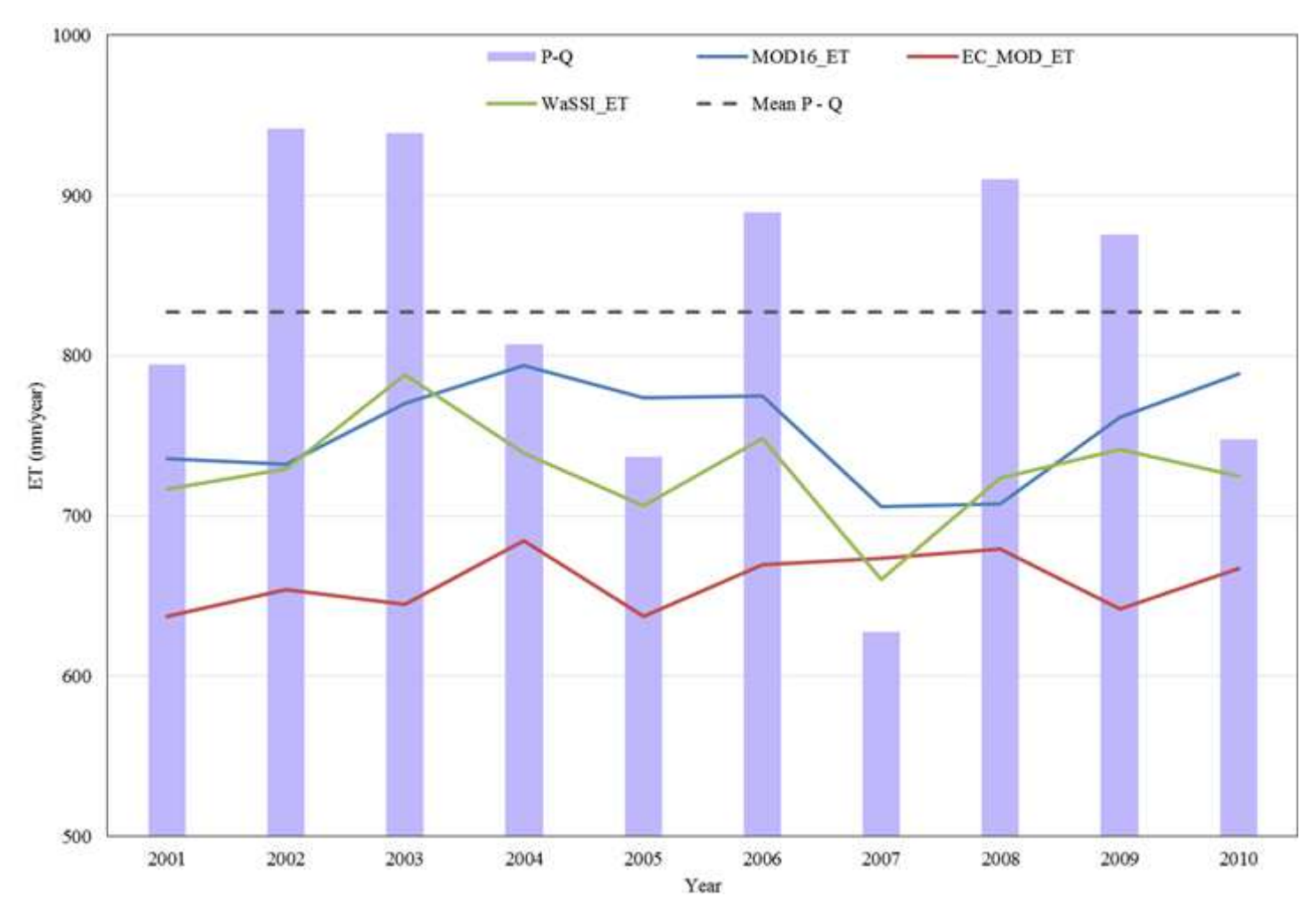

Fig. 7. Validation of annual evapotranspiration (ET) with different data sources for the Upper Neuse River Basin in North Carolina (2001-2010)

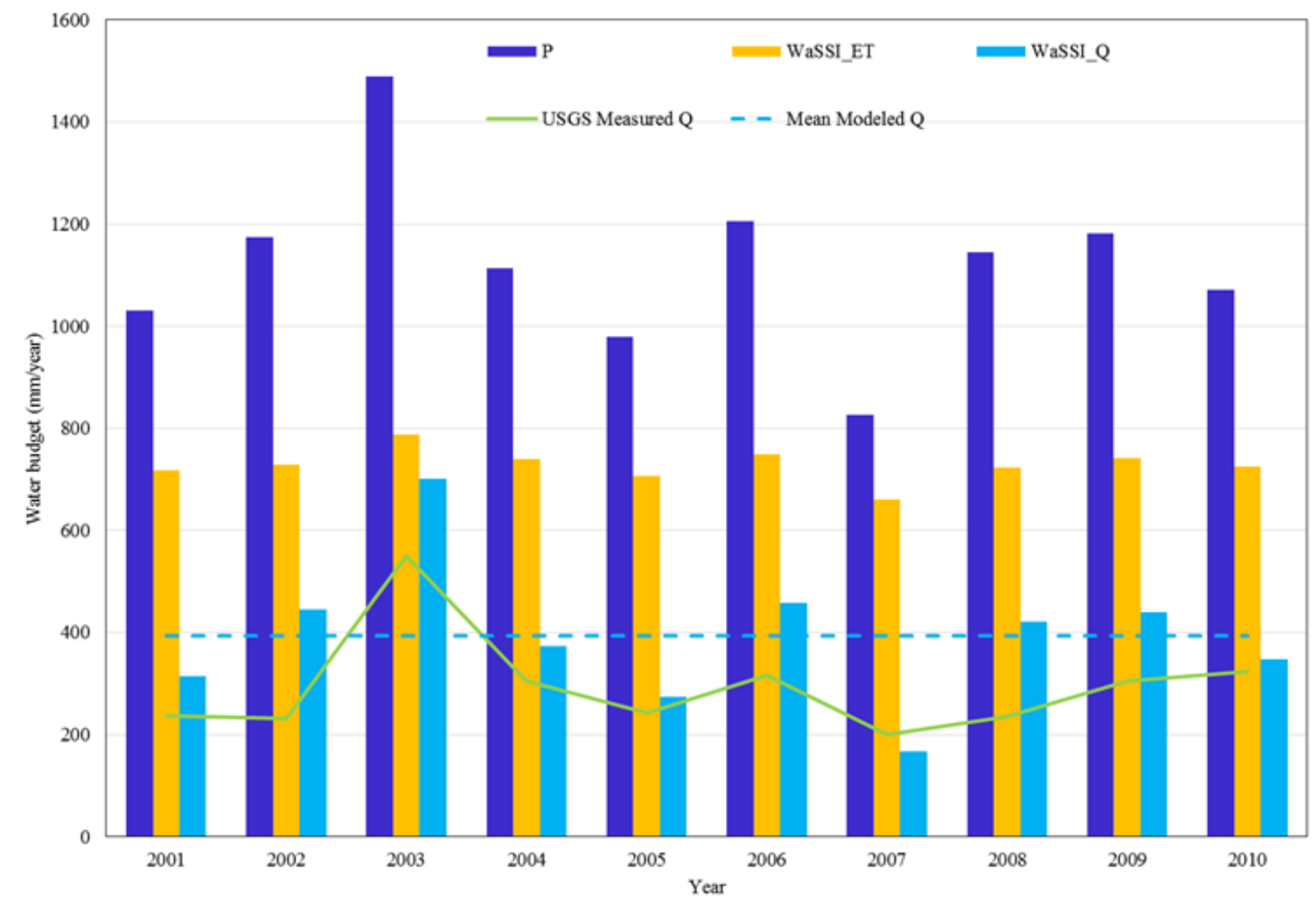

Fig. 8. Measured precipitation and streamflow and modeled water budgets for the Upper Neuse River Basin in North Carolina (2001-2010) 


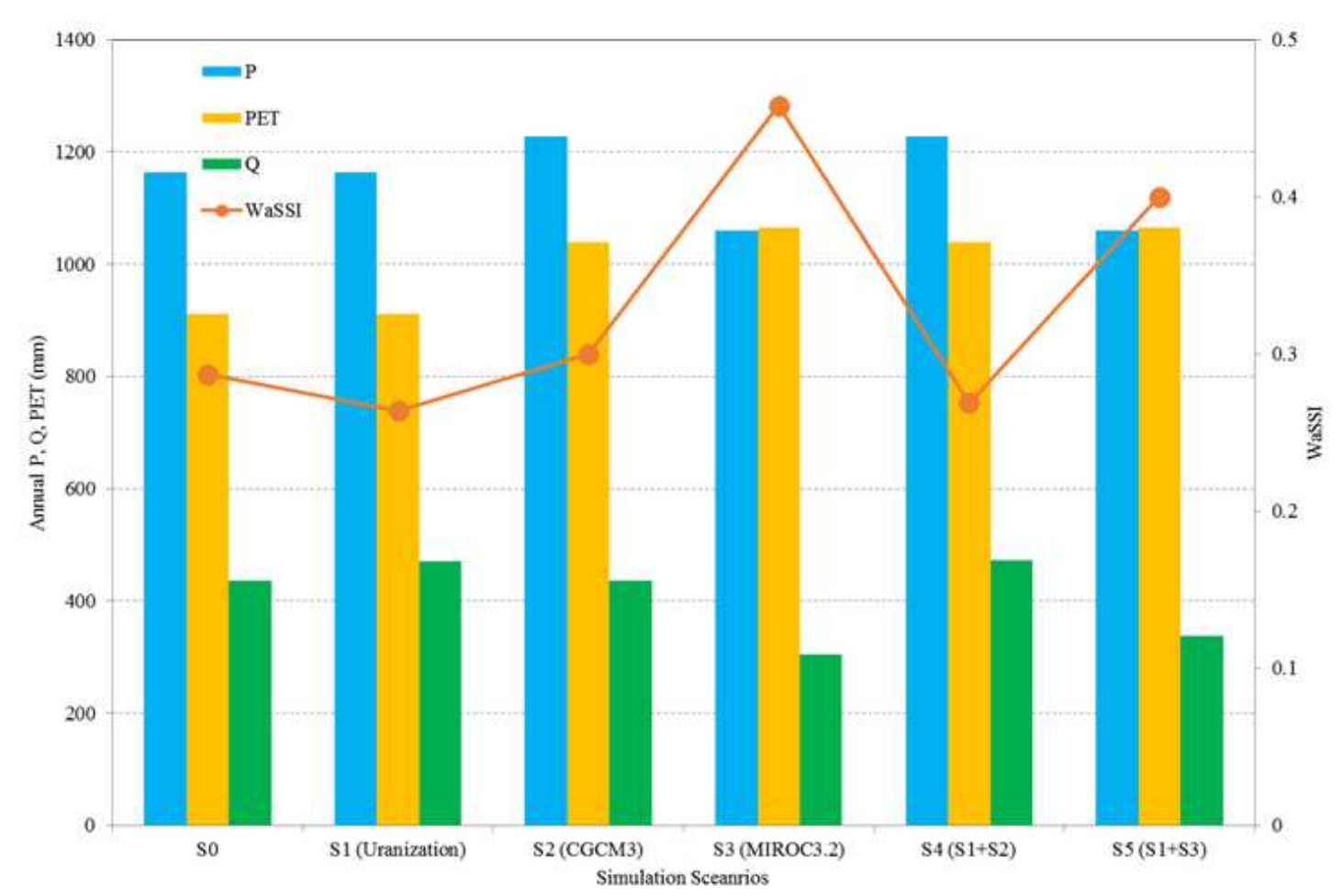

Fig. 9. Current and future (2050) annual water yield (Q) and Water Supply Stress Index (WaSSI = demand/supply) simulated by the WaSSI model

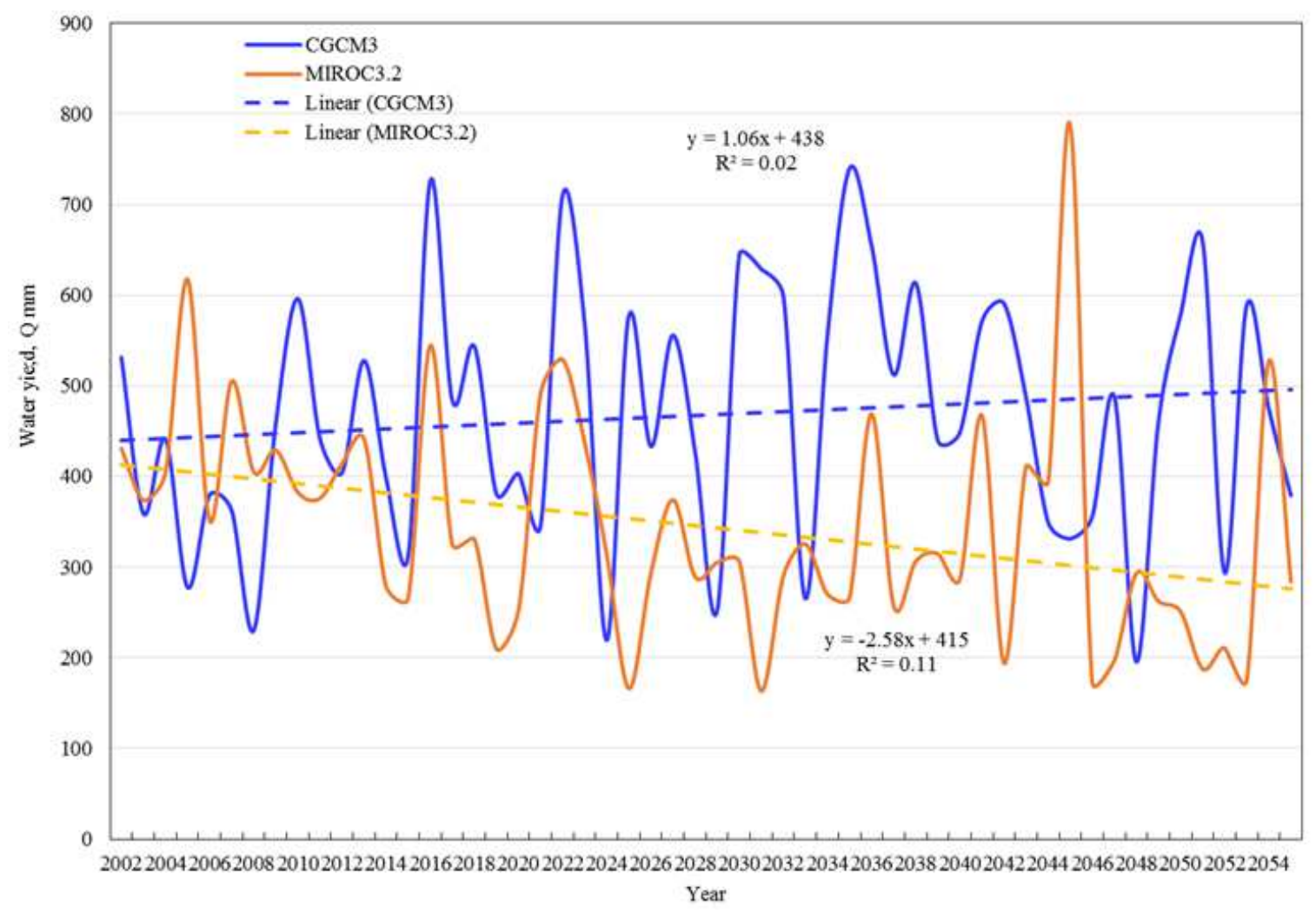

Fig. 10. Effects of climate change on annual water yield (Q) simulated by the WaSSI model 


\section{Conclusion}

Our study indicated that some climate change scenario (MIROC3.2) could overwhelm the hydrological effects of urbanization by 2050. Large scale urbanization can cause substantial increases in runoff. However, the increase in flow was notable to alleviate water supply stress caused by severe future climate change as characterized by climatic variability (e.g., droughts or floods). In addition, urbanization may cause more water pollution due to higher runoff and water quality degradation. Therefore, urbanization would aggravate environmental concerns under future climate change.

Although most GCMs agree on the direction of air temperature change, large uncertainties remain in future precipitation changes and therefore inaccurate predictions of water budgets and water supply for cities. While the CGCM3 scenario predicted that runoff in the UNRB would not change much, the MIROC 3.2 scenario predicted that water yield would decrease and water supply stress would increase. Water resource managers should evaluate the risk of water supply shortages.

It is challenging to predict what impacts future climate change will have on water resources at a local watershed scale. Future climate change models should reduce model uncertainty in projected precipitation so that predictions of water resources will be more consistent and more useful for watershed planning and management.

\section{Acknowledgement}

Funding support for this study was provided in part by the Eastern Forest Environmental Threat Assessment Center, Southern Research Station, USDA Forest Service. Support for Chong Liu was provided by the China Scholarship Council.

\section{Authors' Contributions}

Michelle Tong Sun: Initiated the study, performed the model runs and drafted the paper while working as a USDA Forest Service Intern.

Ge Sun: Supervised Michelle Sun in WaSSI model runs; Helped research design, reviewed and revised the draft.

Chong Liu: Performed WaSSI model validation in modeling runoff and MODDIS ET while visiting the University of North Carolina-Chapel Hill.

Jennifer Anne Moore Myers: Supervised Michelle Sun and contributed manuscript writing and revisions.

Steven George McNulty: Provided advice to Michelle Sun on model runs, research design, hypothesis test and reviewed modeling results.

\section{Ethics}

The authors declare no conflicts of interest.

\section{References}

Averyt, K., J. Meldrum, P.V. Caldwell, G. Sun and S.G. McNulty et al., 2013. Sectoral contributions to surface water stress in the coterminous United States U.S. Environ. Res. Let.

DOI: $10.1088 / 1748-9326 / 8 / 3 / 035046$

Caldwell, P.V., G. Sun, S.G. McNulty, E.C. Cohen and J.A.M. Myers, 2012. Impacts of impervious cover, water withdrawals and climate change on river flows in the conterminous US. Hydrol. Earth Syst. Sci., 16: 2839-2857.

DOI: $10.5194 /$ hess-16-2839-2012

Caldwell, P.V., G. Sun, S.G. McNulty, E.C. Cohen and J.A.M. Myers, 2011. Modeling Impacts of Environmental Change on Ecosystem Services across the Conterminous United States. In: Observing, Studying and Managing for Change, Medley, C.N., G. Patterson and M.J. Parker, (Eds.), USGS Science for a Changing World, pp: 202-202.

CCSP, 2014. The Effects of Climate Change on Agriculture, Land Resources, Water Resources and Biodiversity in the United States. 1st Edn., Createspace Independent Pub, ISBN-10: 1500397385, pp: 250.

Coulson, D.P., L.A. Joyce, D.T. Price, D.W. McKenney and S.R. Martin et al., 2010. Climate scenarios for the conterminous United States at the county spatial scale using SRES scenarios B2 and PRISM climatology. U Department of Agriculture.

Daly, C., M. Halbleib, J.I. Smith, W.P. Gibson and M.K. Doggett et al., 2008. Physiographically sensitive mapping of climatological temperature and precipitation across the conterminous United States. Int. J. Climatol., 28: 2031-2064.

DOI: $10.1002 /$ joc. 1688

IPCC, 2014. Climate Change 2013: The Physical Science Basis: Working Group I Contribution to the Fifth Assessment Report of the Intergovernmental Panel on Climate Change. 1st Edn., Cambridge University Press, ISBN-10: 110705799X, pp: 1552.

Kenny, J.F., N.L. Barber, S.S. Hutson, K.S. Linsey and J.K. Lovelace et al., 2009. Estimated use of water in the United States in 2005. 1st Edn., United States Geological Survey, ISBN-10: 1411326008, pp: 52.

Kundzewicz, Z.W., L.J. Mata, N.W. Arnell, P. Döll and P. Kabat et al., 2007. Freshwater Resources and Their Management. In: Climate Change 2007: Impacts, Adaptation and Vulnerability: Contribution of Working Group II to the Fourth Assessment Report of the Intergovernmental Panel on Climate Change, Parry, M.L., (Ed.), Cambridge University Press, Cambridge, U.K., ISBN-10: 0521880106, pp: 976. 
Liu, N., P.S. Sun, S. Liu and G. Sun, 2013. Coupling simulation of water-carbon processes for catchmentcalibration and validation of the WaSSI-C model. Chin. J. Plant Ecol., 37: 492-502. DOI: $10.3724 /$ SP.J.1258.2013.00051

Lockaby, G., C. Nagy, J.M. Vose, C.R. Ford, G. Sun and S.G. McNulty et al., 2011. Water and Forests. In: The Southern Forest Futures Project: Technical Report. Wear, D.N. and J.G. Greis, (Eds.), U.S. Department of Agriculture, Forest Service, Southern Research Station, pp: 54-54.

McDonald, R.I., P. Green, D. Balk, B.M. Fekete and C. Revenga et al., 2011. Urban growth, climate change and freshwater availability. Proc. National Acad. Sci., 108: 6312-6317. DOI: $10.1073 /$ pnas. 1011615108

McNulty, S.G., E.C. Cohen, G. Sun and P.V. Caldwell, 2015. Chapter 1.7: Hydrologic Modelling for Water Resource Assessment in a Developing Country: The Rwanda Case Study. In: Watershed Modeling. Lafforgue, M., (Ed.).

Mu, Q.Z., M.S. Zhao and S.W. Running, 2011. Improvements to a MODIS global terrestrial evapotranspiration algorithm. Remote Sensing Environ., 115: 1781-1800. DOI: $10.1016 /$ j.rse.2011.02.019

Nash, J.E. and J.V. Sutcliffe, 1970. River flow forecasting through conceptual models part I-A discussion of principles. J. Hydro., 10: 282-290. DOI: 10.1016/0022-1694(70)90255-6

NCA, 2014. Climate change impacts in the United States: The third national climate assessment. U.S. Global Change Research Program.

O'Driscoll, M., S. Clinton, A. Jefferson, A. Manda and S. McMillan, 2010. Urbanization effects on watershed hydrology and in-stream processes in the southern United States. Water, 2: 605-648. DOI: $10.3390 /$ w2 2030605

Sun, G., P. Caldwell, A. Noormets, E. Cohen and S.G. McNulty et al., 2011a. Upscaling key ecosystem functions across the conterminous United States by a water-centric ecosystem model. J. Geophysical Res. DOI: 10.1029/2010JG001573

Sun, G., K. Alstad, J. Chen, S. Chen and C.R. Ford et al., 2011b. A general predictive model for estimating monthly ecosystem evapotranspiration. Ecohydrology, 4: 245-255.
Sun, G. and B.G. Lockaby, 2012. Chapter 3: Water Quantity and Quality at the Urban-Rural Interface. In: Laband, D.N., B.G. Lockaby and W. Zipperer, (Eds.), Urban-Rural Interfaces: Linking People and Nature, American Society of Agronomy, Madison, WI, ISBN-10: 0891186158, pp: 26-45.

Sun, G., P.V. Caldwell, A.P. Georgakakos, S. Arumugam and J. Cruise et al., 2013. Chapter 10. Impacts of Climate Change and Variability on Water Resources in the Southeastern US. In: Southeastern Regional Technical Report to the National Climate Change Assessment. Ingram, K.T., K. Dow and L. Carter (Eds.), Island Press, pp: 210-236.

Sun, G., P.V. Caldwell and S.G. McNulty, 2015. Modelling the potential role of forest thinning in maintaining water supplies under a changing climate across the conterminous United States. Hydrological Proc. DOI: 10.1002/hyp.10469

Sun, G., S.G. McNulty, J.A.M. Myers and E.C. Cohen, 2008. Impacts of multiple stresses on water demand and supply across the southeastern United States. J. Am. Water Resour. Associat., 44: 1441-1457. DOI: $10.1111 / \mathrm{j} .1752-1688.2008 .00250 . \mathrm{x}$

Tavernia, B.G., M.D. Nelson, P.V. Caldwell and G. Sun, 2013. Water stress projections for the northeastern and Midwestern united states in 2060: Anthropogenic and ecological consequences. J. Am. Water Resour. Associat., 49: 938-952. DOI: $10.1111 /$ jawr.12075

Xiao, J.F., S.V. Ollinger, S. Frolking, G.C. Hurtt and D.Y. Hollinger et al., 2014. Data-driven diagnostics of terrestrial carbon dynamics over North America. Agric. Forest Meteorol., 197: 142-157.

DOI: 10.1016/j.agrformet.2014.06.013

Zarnoch, S.J., H.K. Cordell, C.J. Betz, J. Carter and L. Langner, 2010. Projecting County-Level Populations Under three Future Scenarios: A Technical Document Supporting the Forest Service 2010 RPA Assessment. 1st Edn., U.S. Department of Agriculture Forest Service, Asheville, NC, pp: 8. 